\title{
ORIGINAL ARTICLE HIV and the urban homeless in Johannesburg
}

\author{
G M Lohrmann, B Botha, A Violari, G E Gray \\ Chris Hani Baragwanath Academic Hospital, Johannesburg \\ G M Lohrmann, MB BCh \\ Trinity Health Services, Johannesburg \\ B Botha, MPhil
}

Perinatal HIV Research Unit, Chris Hani Baragwanath Academic Hospital, Johannesburg

A Violari, MD, FCPaed (SA)

G E Gray, MB BCh, FCPaed (SA)

Corresponding author: G M Lohrmann (graham.lohrmann@gmail.com)

\begin{abstract}
Background. There are few data on HIV prevalence and risk factors among inner-city homeless and marginally housed individuals in South Africa.

Methods. We recruited 136 adults from a Johannesburg inner-city homeless clinic; mean age was 32.4 years, 129 (95\%) were male, and 90 (66\%) were of South African nationality. Participants were tested for HIV and answered a short demographic survey. Descriptive statistics and uni- and multivariate regression analyses were used for data analysis.

Results. The HIV prevalence in the cohort was $23.5 \%$. Transactional sex, relationship status, number of concurrent sexual partners, condom usage and history of previously treated sexually transmitted infections (STIs), living on the street, the use of alcohol or drugs, and previous exposure to voluntary counselling and testing (VCT), were not significant risk factors for HIVpositivity. Statistically significant HIV risk factors on multivariate analysis included the presence of an STI (odds ratio (OR) 5.6; $p<0.01$ ) and unemployment (OR 6.7; $p<0.01$ ). South African nationality was a significant risk factor on univariate analysis (OR 2.99; $p<0.05$ ), but not on multivariate analysis (OR 2.2; $p=0.17$ ).

Conclusion. The HIV prevalence in the sample did not differ appreciably from HIV prevalence estimates in other at-risk populations in similar settings, suggesting that homelessness in a South African city alone may not be a significant risk factor for HIV infection. HIV prevention efforts cannot be restricted to behaviour change programmes, but must be more holistic, recognising the protective role that employment has on HIV incidence.
\end{abstract}

S Afr J HIV Med 2012;13(4):174-177. DOI:10.7196/SAJHIVMED.837

South Africa (SA) bears a significant burden of the HIV epidemic, with an estimated $18.8 \%$ of the adult population (aged 15 - 49 years) infected. ${ }^{1}$ However, the prevalence of HIV within an essentially homeless population, as found in the city centre of Johannesburg, is not known. Research performed predominantly in developed countries suggests a substantially higher HIV and sexually transmitted infection (STI) burden among the homeless and marginally housed. ${ }^{2-4}$

The relationship between HIV infection, employment status and homelessness is complex. It is well documented that HIV leads to neuropsychological impairment, ${ }^{5}$ potentially leading to decreased job performance and unemployment, with up to $65 \%$ of HIV-infected individuals unemployed, even in developed countries. ${ }^{6,7}$ Unemployment in turn leads to food insecurity, which has been associated with an increased risk of contracting HIV and lower CD4 counts. ${ }^{8}$ The homeless are also at risk of psychiatric illness and have a decreased awareness of $\mathrm{HIV}^{3}$ both of which may affect uptake of prevention and/or treatment interventions. ${ }^{9}$ In addition, the majority of the homeless in SA urban settings are male, and hence more difficult to reach with HIV interventions. ${ }^{10}$ To gain a better understanding of these issues and to inform future HIV prevention strategies, we investigated the HIV prevalence and risk factors among urban homeless individuals in Johannesburg.

\section{Methods}

We performed a cross-sectional survey of 136 adults attending a Johannesburg inner-city centre soup kitchen and clinic, operated by a local non-governmental organisation. Participants were sampled conveniently and classified as homeless or marginally housed. Data were collected for 1 year commencing 1 April 2010. HIV testing was performed using 2 rapid finger prick tests from separate manufacturers. A third confirmatory test was used in the case of discordant results. We 
also included 6 individuals who had proof of a previous HIV-positive test result. Exclusion criteria included: (i) earnings in excess of R5 000/ month; and (ii) residing in a house defined on the grounds of a solid permanent structure with basic amenities (water, electricity, sewerage) and that is under the ownership or rental of the participant or family (excluding anything considered to be a form of shelter).

Ethics approval was obtained from the Human Research Ethics Committee of the University of the Witwatersrand. HIV risk factors were identified by uni- and multivariate logistic regression analysis. Data were represented as odds ratios (ORs) with 95\% confidence intervals (CIs).

\section{Results}

Sample characteristics are summarised in Table 1. The HIV prevalence was $23.5 \%$ (95\% CI 16.4\% - 30.7\%). Mean participant age was 32.4 years with $129(95 \%)$ of the adults being male and $46(35 \%)$ being foreigners.

\section{Table 1. Sample characteristics}

\begin{tabular}{|c|c|c|c|}
\hline \multirow[b]{3}{*}{ Characteristic } & \multicolumn{3}{|c|}{$N(\%)$} \\
\hline & Total & HIV-positive & HIV-negative \\
\hline & $136(100)$ & $32(100)$ & $104(100)$ \\
\hline \multicolumn{4}{|l|}{ HIV test result } \\
\hline Positive & $32(24)$ & $32(100)$ & $0(0)$ \\
\hline Negative & $104(76)$ & $0(0)$ & $104(100)$ \\
\hline \multicolumn{4}{|l|}{ Gender } \\
\hline Male & $129(95)$ & $29(91)$ & $100(96)$ \\
\hline Female & $7(5)$ & $3(9)$ & $4(4)$ \\
\hline \multicolumn{4}{|l|}{ Residence } \\
\hline Street & $68(51)$ & $21(66)$ & $47(45)$ \\
\hline Shelter & $30(22)$ & $6(19)$ & $24(23)$ \\
\hline Informal settlement & $8(6)$ & $2(6)$ & $6(6)$ \\
\hline House & $28(21)$ & $3(9)$ & $25(24)$ \\
\hline \multicolumn{4}{|l|}{ Marital status } \\
\hline Married & $14(11)$ & $3(10)$ & $11(11)$ \\
\hline Single & $91(73)$ & $21(72)$ & $70(73)$ \\
\hline Widowed & $20(16)$ & $5(17)$ & $15(16)$ \\
\hline \multicolumn{4}{|l|}{ Nationality } \\
\hline South African & $87(65)$ & $26(84)$ & $61(60)$ \\
\hline Other & $46(35)$ & $5(16)$ & $41(40)$ \\
\hline \multicolumn{4}{|l|}{ Employment status } \\
\hline Employed & $55(42)$ & $7(22)$ & $52(50)$ \\
\hline Unemployed & $77(58)$ & $25(78)$ & $52(50)$ \\
\hline \multicolumn{4}{|l|}{ Education level } \\
\hline$<$ Grade 12 & $70(62)$ & $15(54)$ & $55(56)$ \\
\hline Grade 12 & $48(38)$ & $13(46)$ & $35(35)$ \\
\hline Tertiary & $9(7)$ & $0(0)$ & $9(9)$ \\
\hline \multicolumn{4}{|l|}{ Reason for testing } \\
\hline Multiple partners & $6(4)$ & $3(9)$ & $3(3)$ \\
\hline Partner HIV-positive or advised by family/friends & $5(4)$ & $0(0)$ & $5(5)$ \\
\hline Feeling unwell or advised by health worker & $42(31)$ & $22(68)$ & $20(19)$ \\
\hline Retesting (confirming HIV-positive test) & $3(2)$ & $3(9)$ & $0(0)$ \\
\hline Curious about status & $96(71)$ & $15(47)$ & $81(78)$ \\
\hline Partner's behaviour or stopping condoms & $14(10)$ & $1(3)$ & $13(13)$ \\
\hline Other & $8(6)$ & $1(3)$ & $7(7)$ \\
\hline \multicolumn{4}{|l|}{ Result of most recent HIV test } \\
\hline Positive & $12(16)$ & $11(55)$ & $1(2)$ \\
\hline Negative & $61(82)$ & $8(40)$ & $52(98)$ \\
\hline Did not collect & $1(1)$ & $1(5)$ & $0(0)$ \\
\hline \multicolumn{4}{|l|}{ Current exposures } \\
\hline Current STI & $23(17)$ & $11(35)$ & $12(12)$ \\
\hline Cough for $>1$ week & $27(20)$ & $10(32)$ & $17(17)$ \\
\hline Alcohol on most days & $40(30)$ & $10(31)$ & $30(29)$ \\
\hline Smoking on most days & $65(48)$ & $19(59)$ & $46(45)$ \\
\hline Recreational drug use in preceding week & $16(12)$ & $3(9)$ & $13(13)$ \\
\hline Condom use at last sexual encounter & $91(51)$ & $21(44)$ & $70(53)$ \\
\hline
\end{tabular}


Table 1. Sample characteristics (continued)

\begin{tabular}{|c|c|c|c|}
\hline \multirow[b]{3}{*}{ Characteristic } & \multicolumn{3}{|c|}{$N(\%)$} \\
\hline & Total & HIV-positive & HIV-negative \\
\hline & $136(100)$ & $32(100)$ & $104(100)$ \\
\hline \multicolumn{4}{|l|}{ VCT } \\
\hline Previous HIV testing and counselling & $65(49)$ & $15(50)$ & $50(49)$ \\
\hline \multicolumn{4}{|l|}{ Exposure in preceding 12 months } \\
\hline Vaginal or anal intercourse & $114(84)$ & $26(81)$ & $88(85)$ \\
\hline Blood transfusion or medical injection & $45(33)$ & $11(34)$ & $34(33)$ \\
\hline Intercourse after alcohol or illicit drugs & $65(48)$ & $17(50)$ & $48(46)$ \\
\hline Transactional sexual intercourse & $18(13)$ & $7(22)$ & $11(11)$ \\
\hline Had oral sex & $28(21)$ & $6(19)$ & $22(21)$ \\
\hline Sexual intercourse without a condom & $55(40)$ & $14(44)$ & $41(39)$ \\
\hline Symptoms of an STI & $26(19)$ & $11(34)$ & $15(14)$ \\
\hline Diagnosed with an STI & $16(12)$ & $7(22)$ & $9(9)$ \\
\hline
\end{tabular}

Table 2. Risk factors for HIV using logistic regression*

\begin{tabular}{|c|c|c|c|c|}
\hline \multirow[b]{2}{*}{ Risk factor } & \multicolumn{2}{|c|}{ Univariate } & \multicolumn{2}{|c|}{ Multivariate } \\
\hline & OR (95\% CI) & $p$-value & OR (95\% CI) & $p$-value \\
\hline Unemployment & $3.7(1.4-9.8)$ & 0.009 & $6.7(1.8-25.6)$ & 0.006 \\
\hline South African nationality & $2.99(1.12-7.9)$ & 0.028 & $2.2(0.7-7.0)$ & 0.170 \\
\hline Current STI & $3.7(1.4-9.8)$ & 0.008 & $5.6(1.5-20.7)$ & 0.010 \\
\hline
\end{tabular}

The mean monthly income for the HIVpositive and -negative groups was R 485 (95\% CI R176 - R794) and R 863 (95\% CI R540 - R1 186), respectively. There was no relationship between HIV-seropositivity and relationship status, educational level, number of sexual partners, smoking or use of alcohol, illicit drugs or condoms.

Previous exposure to voluntary counselling and testing (VCT) was not protective against $\mathrm{HIV}$ in this sample, as the number of previous tests was marginally higher in the HIV-positive group (1.6 v. $1.2 ; p>0.05)$. Of patients who tested HIV-positive, $36.3 \%$ had had a previous positive test result elsewhere, but had never been followed up in terms of CD4 count or antiretroviral therapy (ART) initiation. During post-test counselling, both HIV-positive and -negative groups reported unwillingness to disclose their status to others (59\% and 50\%, respectively).

The results of logistic regression modelling are shown in Table 2. There was a significant association between HIV-positive status and unemployment (OR 6.7; 95\% CI 1.8 - 25.6; $p=0.006$ ), and current STI (OR 5.6; 95\% CI
$1.5-20.7 ; p=0.010)$. South African nationality was associated with HIV seropositivity on univariate analysis (OR 2.2; 95\% CI 1.12 - 7.9; $p=0.028$ ), but not multivariate analysis (OR 2.2 ; $95 \%$ CI $0.7-7.0 ; p=0.17$ ).

\section{Discussion}

The associations between homelessness and HIV in this study contrast markedly with international literature, in terms of absolute risk and behaviour patterns. The HIV prevalence in our study was high by international standards, but not substantially greater than that of a general SA population of similar age and gender. ${ }^{12,13}$ Furthermore, no association was found between drug use and HIV in our sample, although this is a well-documented HIV risk factor in homeless populations in Europe and North America. ${ }^{2-4}$

HIV incidence in SA has only recently begun to plateau, with no consensus on the reason for this. It is unclear whether the successes of education and prevention programmes are finally being felt, or if increased access to ART and STI treatment are at play. Evidence suggests that HIV education and prevention programmes may not have had a significant effect on HIV status in our sample. For example, previous exposure to VCT did not appear to be protective against $\mathrm{HIV}$, and the patterns of risk behaviour were similar between HIV-positive and -negative individuals. However, the association between HIV status and unemployment was significant, because it linked unemployment to HIV risk, rather than the more simplistic factor of homelessness.

Overall, the results of our study suggest that the dynamics of HIV among the urban homeless in SA may be different from other settings. High levels of inequality and unemployment, especially in an urban environment, lead to a unique set of risk factors which differ from that of the developed world. In SA, simply being homeless or marginally housed may not put individuals at increased risk of HIV compared with the general population. However, unemployment needs to be addressed to mitigate the effect of the HIV epidemic in this setting. 


\section{References}

1. National Department of Health (DoH). HIV \& AIDS and STI Strategic Plan for South Africa 2007 - 2011. Pretoria: DoH, 2008.

2. Shakarishvili A, Dubovskaya LK, Zohrabyan LS, et al. Sex work, drug use, HIV infection, and spread of sexually transmitted infections in Moscow, Russian Federation. Lancet 2005;366(9479):57-60.

3. Tynes LL, Sautter FJ, McDermott BE, Winstead DK. Risk of HIV infection in the homeless an chronically mentally ill. S Afr Med J 1993;86(3):276281.

4. Bangsberg DR, Hecht FM, Charlebois ED, et al. Adherence to protease inhibitors, HIV-1 viral load, and development of drug resistance in an indigent population. AIDS 2000;14(4):357-366.

5. Heaton RK, Velin RA, McCutchan JA, et al Neuropsychological impairment in human immunodeficiency virus-infection: implications fo employment. HNRC Group. HIV Neurobehavioral
Research Center. Psychosom Med 1994;56(1):8-17. 6. Dray-Spira R, Gueguen A, Lert F; VESPA Study Group. Disease severity, self-reported experience of workplace discrimination and employment loss during the course of chronic HIV disease: Differences according to gender and education. Occup Environ Med 2008;65(2):112-119. [http:// dx.doi.org/10.1136/oem.2007.034363]

7. Dray-Spira R, Lert F; VESPA Study Group. Living and working with HIV in France in 2003: Results from the ANRS-EN12-VESPA Study. AIDS 2007;21(1):S29-S36. [http://dx.doi.org/10.1097/01. aids.0000255082.31728.52]

8. Weiser SD, Bangsberg DR, Kegeles S, Ragland K, Kushel MB, Frongillo EA. Food insecurity among homeless and marginally housed individuals living with HIV/ AIDS in San Francisco. AIDS Behav 2009;13(5):841848. [http://dx.doi.org/10.1007/s10461-009-9597-z]

9. Tsai AC, Weiser SD, Petersen ML, Ragland $\mathrm{K}$, Kushel MB, Bangsberg DR. A marginal structural model to estimate the causal effect of antidepressant medication treatment on viral suppression among homeless and marginally housed persons with HIV. Arch Gen Psychiatry 2010;67(12):1282-1290. [http://dx.doi.org/10.1001/ archgenpsychiatry.2010.16]

10. Nglazi MD, van Schaik N, Kranzer K, Lawn SD, Wood R, Bekker LG. An incentivized HIV counseling and testing program targeting hard-toreach unemployed men in Cape Town, South Africa I Acquir Immune Defic Syndr 2012;59(3):e28-e34 [http://dx.doi.org/10.1097/QAI.0b013e31824445f0]

11. Shisana O, Rehle T, Simbayi LC, et al. South African national HIV prevalence, HIV incidence, behaviour and communication survey. Durban: Human Sciences Research Council Press, 2005.

12. UNAIDS/WHO. AIDS Epidemic Update December 2006. UNAIDS/WHO 2006. http://data.unaids org/pub/epireport/2006/2006_epiupdate_en.pdf (accessed 1 August 2012). 